\title{
Mundane: Thinking through All This Can Happen
}

Gareth Evans

\begin{abstract}
What if ... a text (Walser's Walk) becomes image and sound and movement and new, and then becomes text again? This writing reflects on how images make history, now, on editing as placement and embodiment, on things bearing witness to things which must be borne witness to, and on rabbit holes of frames that might conjure up the world.
\end{abstract}

Keywords: image, sound, edits, All This Can Happen, Davies, Hinton

Where I am, I don't know, I'll never know, in the silence you don't know, you must go on, I can't go on, I'll go on.

- Samuel Beckett ${ }^{1}$

Always there is the war. The war and the bodies it makes. The shuddering stare, the stumble and fall-always bodies falling through the conflict-knotted air. The stumbling stare, the shudder and stall. The stopped and the starting, barely, again.

To harrow the phenomenal. To shake the head out, almost off. Jolt it clear of horrors, corpses piled in corridors of mind. To put the lights out on this territory, to raise them on another place entirely.

Blinds up. Time for gentler looking.

*

Once there was a person (was a man), who woke into the waking dream of life, and streets, and all the people coming forth by day. The health that comes from being out and in it, walking.

"[A]s if I saw it for the first time ..."2

A jumping girl waiting to land on her own shadow; even if only that, then a world, but a world becoming "modern," becoming its own image through immediate reproduction, faster than the most of people can, what, keep up with. Which is why a walk, in the midst of working hours, as the medium of encounter, is already a subversion, an oppositional proposal. Where others are labouring and in the middle of 
the rush to maintain at least a balance or an equilibrium with the accelerating social, architectural, and technological times crowding in upon them, the person in question embarks, like a vessel on a once and brilliant morning, solely for the pleasure of the voyage.

So there's surely no surprise then that the presiding spirit of both this walk, imaged and imagined for us by Davies and Hinton in their quietly ecstatic and empathetic advocacy of sensual and intellectual witness, is Alice with her wonder entourage-all unceasing curiosity and sliding shifts of scale, and the rabbit holes of frames and bright arcades, and altered realities of every hue and consequence.

Make it new. Wash clean our eyes of happenstance we know, or know through all our tired ways of seeing...

*

For a work that is telling both a walk (through a place that makes topographic sense, however nominally a fiction) and a film constructed from shards of time and territory, the resolved site of the finished piece lies intriguingly elsewhere, in a triangulation between the elements, in the zone delineated between subject, story, and filmic strategy. From one perspective, this is a huge terrain - swathes of human, natural, and societal life. From another, it is tiny, because the integration of these three positions is so intimate, so neighbourly; the intentions of each are so mutual and so strikingly interdependent, that there is almost no distance between them. In fact, it might be said that the difference is only the width of a threshold or, to use a more relevant term here, the size of an edit.

And this is what is most remarkable, perhaps. Under Davies' and Hinton's scrutiny and care, the edit, the precise deliberation about image (an image, many images) and relations-first to duration, then with its own echo, repeat, refrain, or variation, and then to its placing (within the larger canvas of the screen) in dialogue or polylogue with others-becomes in a profound and ongoing sense the film itself. Of course, an edit can only exist if two frames or sequences previously exist and are able to be joined. But here, an unusual motivational alchemy has occurred. The edit is less a technical procedure than an embodiment, by which the experience of being aliveand the perceptual devices through which that living realises itself to be so-are conveyed.

This has come about partly because of the deployment entirely of found footage (that is, images with other purposed lives), or because of the choreographic impulse that underlies the project and the trajectories of both primary makers. Both strategies prioritise-as a walk does-process over arrival, encounter over ownership. The edit, therefore, is the agent of these approaches. The edit is the eyes or the ears in their ceaseless roving through the real. While every singular story of each moment is, in and 
of itself, immeasurably precious and unequivocal, it is the passage that enables and ennobles their presence in the work as fully taken. Qualities of the "positive" or "negative," of happiness or regret, anger or longing, are less important than the fact that they are all endowments of the living, of the undeniably existent.

This passage-of the writer/walker and the finder/film-makers-is equivalent in each medium, in each transaction, with the multifarious. It is this rigorous, shared intention that grants All This Can Happen its potency; and it is, as noted, undeniably choreographic in intention and realisation: bodies engaged in all the movements of the daily, writing their chorus dance (choreography's etymology) into the mornings, afternoons, and dusk - that is the single doorway into every ancient evening.

"The soul of the world had opened."

Forest joys, a woman's meadow mystery, flower heads of songs, the tang and taste of almost a seduction...

There is a return to founding principles here, to ground tools: event first, then the recollection, but, in both, an animation; the breathing-into-being of things. Animation, in an enrichment of its cinematic sense, delivers the motion-capture of the soul (the anima) of objects, creatures, characters. Here engages a carefully woven relationship with democracy, with a general assembly of looking, with a full spectrum priority: all things carry and convey; all things bear witness and must be borne witness to; everything is illuminated, whether seeding burst or animal, woman or the weather, business or a building, worker or such woodland, gesture or the book.

This originating animation determines in its turn the aesthetic choices regarding the manipulations of the found image-the desire to find visual correlatives, in terms of precise expression, for the perceptual "truth" of that particular image or their sequence (and the latent truth of things within the image), whether in terms of registering its incident, context or this interiority (never imitative, rarely illustrative, always associative, heightening its telling by allusion; imaging the effect, the ripple out from action, the feeling of the walk and all its meetings...)

The project constantly operates on the threshold between order and collapse, between harbour (framing) and open water (dissolution of parameters). These frames rarely hold for long; image and energies spill, redirect themselves, breed, split, stutter, surge. Everyone and everything is multiple. Possibility outruns probability.

"I was no longer myself, was another; and yet it was on this account I became properly myself."

The sensory world, registered so intensely in both text and footage, gives inevitably onto metaphysics. A walk is always, if properly attended, a journey through the event of one's own life, the pressure exerted on it by circumstance and surroundings, and its 
implications. The film's sourcing from diverse decades and regions, its population by numerous avatars of the walker and the watched, speaks as if effortlessly to a "universal" resonance and relevance, while resolutely anchoring and celebrating the tangible, the sensed.

There are hints here, then of the century's aspirations to "total" vision, but this is no panopticon of miserable surveillance, no spyglass for class corralling-although it acknowledges and signs the threat; rather it offers a generous endowment of dignity and worth, the act of acknowledgement, to all that is being visited-collaborations at every step, as richly nuanced as those within the assembly of the piece, from sound to voice, archive mining to front-of-house promotion. All roles are necessary, all tasks contribute. All are company on the journey.

Half a decade ahead of Ulysses and The Waste Land, Walser had journeyed through a total day, had hymned the miraculous momentary, had elegised the constant entropy of things (celluloid decay edging like a tide into the picture), had formed a language out of, and to counter, conflict. Prescience has its price. Prophets speculate less on a future than they speak to the concealed convergences, the simulations and stimulations, the fissures of the found and fragile present.

*

And after all, all of this ... was it just a fever dream of longing for what might never have transpired? A final gasp in night sweats to salvage what might help, or what had helped, or what simply was (and is). Oh, to wrestle, waltz, and walk with matter, with such matter that is "world" and all its songs and glories, mundane gifts of being-be they low or high, hard or soft, sinister or gleaming, still and so they are; and so we were and are.

And Walser, wise beyond his wounds, he left the world he'd worded through and walked. "I am not here to write but to be mad," 3 he said, and paced asylum avenues for decades more of being. But he did still write, and still he wrote, how could he not, in micro-scripts so dense a side of empty envelope could carry forth a novel, texts so tight in their transcribing they moved beyond the legible through codes known just to him, smaller and smaller, writing himself away from things; but, marked on cards and scraps, they seemed yet like some messages sent out, sent back from where he was, somewhere in the continent inside.

Until the very end, the last walk on the last day (Christmas 1956), and Walser, well, he stepped out and he died, writing himself finally back into the world, scripting himself on a page of snow, a bundle in a dark coat, a blot on winter, spilt ink; a presence text that bore him right away. 
He left a body, evidence, and another body, work; but who's to say he's really passed? He's striding out down every written lane, still pausing for the blossom of every wandering line. And now he's held, and more, endures, in every loving frame, nests of sound and image for the birds of history now.

All this could happen surely ... but did it happen?

$*$

\section{mundane (adj.)}

mid-15c., 'of this world,' from Old French mondain: 'of this world, worldly, earthly, secular;' also 'pure, clean; noble, generous' (12c.), from Late Latin mundanus 'belonging to the world' (as distinct from the Church), in classical Latin 'a citizen of the world, cosmopolite,' from mundus 'universe, world,' literally 'clean, elegant;' used as a translation of Greek kosmos (see cosmos) in its Pythagorean sense of 'the physical universe' (the original sense of the Greek word was 'orderly arrangement')." ${ }^{4}$

Yes.

\section{Biography}

Gareth Evans is a writer, presenter, producer and curator of film at the Whitechapel Gallery, London.

Email: home.gareth@googlemail.com

\section{Notes}

${ }^{1}$ Beckett, The Unnamable, 179.

2 All quotations in italics are from All This Can Happen (2012). Dir. Siobhan Davies, David Hinton.

${ }^{3}$ This quotation from Walser is relayed in general anecdote.

${ }^{4}$ Etymology Online, "Mundane." 


\section{References}

All This Can Happen. Dir. Siobhan Davies and David Hinton. UK, 2012. Film.

Beckett, Samuel. The Unnamable. New York: Grove Press. 1958.

"Mundane." Etymology Online. Accessed 9 Oct. 2015.

http://www.etymonline.com/index.php?term=mundane 